\title{
Caspase-8, receptor-interacting protein kinase 1 (RIPK1), and RIPK3 regulate retinoic acid-induced cell differentiation and necroptosis
}

\author{
Masataka Someda $^{1,2} \cdot$ Shunsuke Kuroki ${ }^{1,3} \cdot$ Hitoshi Miyachi $^{4} \cdot$ Makoto Tachibana $^{3} \cdot$ Shin Yonehara $\mathbb{D}^{1,2,4}$
}

Received: 1 July 2019 / Revised: 4 October 2019 / Accepted: 4 October 2019 / Published online: 28 October 2019

(c) The Author(s) 2019. This article is published with open access

\begin{abstract}
Among caspase family members, Caspase- 8 is unique, with associated critical activities to induce and suppress death receptor-mediated apoptosis and necroptosis, respectively. Caspase- 8 inhibits necroptosis by suppressing the function of receptor-interacting protein kinase 1 (RIPK1 or RIP1) and RIPK3 to activate mixed lineage kinase domain-like (MLKL). Disruption of Caspase- 8 expression causes embryonic lethality in mice, which is rescued by depletion of either Ripk3 or $M l k l$, indicating that the embryonic lethality is caused by activation of necroptosis. Here, we show that knockdown of Caspase- 8 expression in embryoid bodies derived from ES cells markedly enhances retinoic acid (RA)-induced cell differentiation and necroptosis, both of which are dependent on Ripk1 and Ripk3; however, the enhancement of RA-induced cell differentiation is independent of $M l k l$ and necrosome formation. RA treatment obviously enhanced the expression of RA-specific target genes having the retinoic acid response element (RARE) in their promoter regions to induce cell differentiation, and induced marked expression of RIPK1, RIPK3, and MLKL to stimulate necroptosis. Caspase- 8 knockdown induced RIPK1 and RIPK3 to translocate into the nucleus and to form a complex with RA receptor (RAR), and RAR interacting with RIPK1 and RIPK3 showed much stronger binding activity to RARE than RAR without RIPK1 or RIPK3. In Caspase-8-deficient as well as Caspase-8- and Mlkl-deficient mouse embryos, the expression of RA-specific target genes was obviously enhanced. Thus, Caspase-8, RIPK1, and RIPK3 regulate RA-induced cell differentiation and necroptosis both in vitro and in vivo.
\end{abstract}

\section{Introduction}

Caspases, members of the cysteine protease family, play an essential role in the induction of apoptosis [1-4].

Edited by R.A. Knight

Supplementary information The online version of this article (https:// doi.org/10.1038/s41418-019-0434-2) contains supplementary material, which is available to authorized users.

Shin Yonehara

yonehara.shin.8s@kyoto-u.ac.jp

1 Graduate School of Biostudies, Kyoto University, Kyoto 6068501, Japan

2 Graduate School of Pharmaceutical Sciences, Kyoto University, Kyoto 606-8501, Japan

3 Graduate School of Frontier Biosciences, Osaka University, Suita 565-0871, Japan

4 Institute for Frontier Life and Medical Sciences, Kyoto University, Sakyo-ku, Kyoto 606-8507, Japan
Caspase- 8 was originally identified as an initiator caspase and mainly functions in the death receptor pathway of apoptosis. Upon ligation of a death receptor such as Fas $[5,6]$, Caspase- 8 is recruited to a complex together with other factors including Fas, Fas-associated death domain (FADD) [7]. Within the complex, proximity-induced auto-cleavage through homo-oligomerization/dimerization catalytically activates Caspase- 8 . The activated Caspase- 8 transmits the death signal mainly to executor caspases including Caspase-3, which then cleave various cellular proteins to complete the apoptosis-inducing process [8]. Caspase- 8 is unique, with associated critical activities not only to induce apoptosis but also to suppress death receptor-mediated necroptosis [9, 10]. Caspase-8 inhibits necroptosis by suppressing the function of receptor-interacting protein kinase 1 (RIPK1) [11-13] to activate mixed lineage kinase domain-like (MLKL), an executer molecule of necroptosis [14]. Disruption of Caspase-8 (Casp8) expression causes embryonic lethality in mice around embryonic day 11.5 (E11.5) [9, 15], which is rescued by depletion of either Ripk3 or $M l k l$, indicating 
that the embryonic lethality is caused by activation of necroptosis [10, 16, 17].

Retinoic acid (RA), which is a metabolic product of vitamin $\mathrm{A}$, is a well-established signaling molecule that plays essential roles in various biological and physiological processes by regulating the expression of RA-specific target genes [18-20]. RA binds to a transcription complex in nucleus, which includes a pair of ligand-activated transcription factors composed of the RA receptor (RAR)-retinoic $\mathrm{X}$ receptor ( $\mathrm{RXR}$ ) heterodimer, to induce transcription of RA-specific target genes. There are three RAR genes (Rara, Rarb, and Rarg) and three RXR genes (Rxra, Rxrb, and $R x r g$ ), and the heterodimeric pair binds to a DNA sequence called a retinoic acid-response element (RARE) [21-23]. Genes containing RARE in their promoters are known to be involved in diverse but interrelated biological processes, such as embryogenesis, growth, and differentiation [24]. Following the successful application of RA in the differentiation therapy of acute promyelocytic leukemia (APL), regulation of RA signaling was also related to differentiation, proliferation or apoptosis of tumor cells $[25,26]$.

\section{Materials and methods}

\section{Mice}

C57BL/6 mice were purchased from CLEA Japan. Casp $8^{-/-}$ mice were generated as described previously [15]. C57BL/6 Casp $8^{+-}$mice were bred and maintained in specific pathogen-free conditions. All experiments in this study were performed according to the guidelines for animal treatment at the institute of Laboratory Animals (Kyoto University).

\section{Cell culture}

TT2 mouse ES cells, a kind gift from R. Kageyama (Kyoto University), were maintained on mitomycin C-treated MEFs in Dulbecco's modified Eagle's medium (DMEM, Gibco) supplemented with $1 \%$ fetal bovine serum (JRH Bioscience), $10 \%$ knockout serum replacement (KSR, Gibco), $2 \mathrm{mM}$ L-glutamine, $0.1 \mathrm{mM} \beta$-mercaptoethanol, $0.1 \mathrm{mM}$ nonessential amino acids (Gibco), $1 \mathrm{mM}$ sodium pyruvate (Gibco), and $1000 \mathrm{U} / \mathrm{ml}$ LIF (CHEMICOM). MEFs, P19 cells, SK-N-SH cells, and HEK293T cells were cultured in Dulbecco's modified Eagle's medium (DMEM, Nacalai Tesque Inc.) supplemented with $10 \%$ fetal bovine serum (Sigma), $100 \mathrm{U} / \mathrm{ml}$ penicillin and $100 \mu \mathrm{g} / \mathrm{ml}$ streptomycin (Nacalai Tesque Inc.). HL60 cells, a kind gift from $\mathrm{K}$. Inaba (Kyoto University), were cultured in suspension culture in RPMI 1640 (Nacalai Tesque Inc.). All cells were cultured at $37^{\circ} \mathrm{C}$ in $5 \% \mathrm{CO}_{2}$. All cell lines were tested for mycoplasma contamination.

\section{Plasmids, lentiviral expression vectors, and shRNA expression system}

pRARE3-Luciferase and an expression vector carrying human RAR $\alpha$ cDNA were kind gifts from A. Kakizuka (Kyoto University). Lentiviral vectors, originally provided by H. Miyoshi (RIKEN), were prepared as described previously [27]. For expression of mouse Casp 8 with shCasp8resistant silent mutations, the corresponding cDNA fragment after site-directed mutagenesis was subcloned into pCSII-PGK-MCS-IRES-Hyg. For expression of mouse $T d g$ and mouse Ripk3 with shRipk3-resistant silent mutations, their corresponding cDNA fragments were subcloned into pCSII-PGK-3xFlag-MCS-IRES-Hyg. To generate stable shRNA-expressing cells, we utilized lentivirus vectors, pCSII-U6-MCS and pCSII-U6-MCS-puro (kind gifts from M. Matsuoka, Kumamoto University). shRNA-encoding DNA oligonucleotides were inserted into these vectors. To achieve the specific knockdown of mouse Casp 8 or Fadd, the tetracycline-inducible shRNA expression system (TetOn shRNA system) with lentivirus-based vectors (pCSIIEF-TetR-IRES-puro and pCSII-U6tet-shCasp 8 or $\operatorname{shFadd-}$ PGK-neo) was utilized in TT2 mouse ES and P19 cells as previously described [27].

The used target sequences of shRNA are listed in Supplementary Table S1.

\section{RA treatment for quantification of RA-induced genes}

Cells were treated with $1 \mu \mathrm{M}, 100 \mathrm{nM}, 10 \mathrm{nM}$, or $1 \mathrm{nM}$ RA (Sigma) for $24 \mathrm{~h}$, and then expression levels of RA-induced genes were quantified. In the case of cells with a Tet-On shRNA system, cells were cultured with or without $1 \mu \mathrm{g} / \mathrm{ml}$ Dox for 4 days, and then treated with or without $1 \mu \mathrm{M}$ RA for $24 \mathrm{~h}$ in the presence of Dox. To analyze expression of genes directly induced by RA, cells were treated with RA for $24 \mathrm{~h}$.

\section{Differentiation of ES cells and P19 cells through EB formation}

After Tet-On shCasp 8 or shFadd ES cells were cultured with or without $1 \mu \mathrm{g} / \mathrm{ml}$ Dox for 2 days, single-cell suspensions were prepared by treatment with trypsin-EDTA (Nacalai Tesque Inc.). To form EBs, $3 \times 10^{3}$ cells were seeded per well in low-cell-adhesion 96-well plates (Thermo SCIENTIFIC) in Glasgow's Minimum Essential Medium (GMEM, Gibco) supplemented with $10 \%$ knockout serum replacement (KSR, Gibco), $2 \mathrm{mM}$ 
L-glutamine, $0.1 \mathrm{mM} \quad \beta$-mercaptoethanol, $0.1 \mathrm{mM}$ nonessential amino acids (Gibco) and $1 \mathrm{mM}$ sodium pyruvate (Gibco) (ES differentiation medium) in the presence of Dox. Two days after seeding, medium was changed to ES differentiation medium supplemented with or without $1 \mu \mathrm{M}$ RA. After 2-day cultivation, formed EBs were transferred to collagen type I-coated chamber slides (Becton Dickinson), cultured for 4 days in ES differentiation medium supplemented with or without $1 \mu \mathrm{M}$ RA (RA treatment was for 6 days in total), and subjected to immunohistochemical analysis. To induce significant differentiation of cells through EB formation, 6 days treatment with RA was necessary.

For RA-induced neural differentiation of Tet-On shCasp8 P19 cells, cells were treated with or without $1 \mu \mathrm{g} / \mathrm{ml}$ Dox for 4 days, and single-cell suspensions were prepared by treatment with trypsin-EDTA (Nacalai Tesque Inc.). To form EBs, $1 \times 10^{6}$ cells were seeded per $10 \mathrm{~cm}$ nontreated dish (IWAKI) in DMEM (Nacalai Tesque Inc.) supplemented with $10 \%$ fetal bovine serum (Sigma), $100 \mathrm{U} / \mathrm{ml}$ penicillin, and $100 \mu \mathrm{g} / \mathrm{ml}$ streptomycin (Nacalai Tesque Inc.), and cultured for 2-6 days with or without $1 \mu \mathrm{M} \mathrm{RA}$.

\section{LDH release assay}

After Tet-On shCasp8 or shCasp8/Ripk3 ES cells were cultured with or without $1 \mu \mathrm{g} / \mathrm{ml}$ Dox for 2 days, singlecell suspensions were prepared by treatment with trypsinEDTA (Nacalai Tesque Inc.). To form EBs, $1.6 \times 10^{5}$ cells were seeded per well in nontreated 6-well plates (IWAKI) in ES differentiation medium in the presence of Dox. Two days after seeding, the medium was changed to ES differentiation medium supplemented with or without $1 \mu \mathrm{M}$ RA and $1 \mu \mathrm{g} / \mathrm{ml}$ Dox. To inhibit necroptosis, cells were cultured with $30 \mu \mathrm{M}$ Nec-1 (Enzo Life Science) thereafter. After a further 2-day cultivation with or without RA, Dox, and Nec-1, the LDH release assay was performed using a Cytotoxicity Detection Kit ${ }^{\text {PLUS }}$ (Roche) in accordance with manufacturer's instructions. At least three biological experiments were carried out and data are presented as means \pm SD.

\section{Western blot analysis and immunoprecipitation}

For western blot analysis, cells were lysed in ice-cold lysis buffer $(20 \mathrm{mM}$ Tris-HCl, pH7.4, with $10 \%$ glycerol, $1 \%$ Triton X-100, $0.5 \%$ Nonidet P-40, $150 \mathrm{mM} \mathrm{NaCl}$, and 1 $\mathrm{mM}$ EDTA) containing a protease inhibitor cocktail (Nacalai Tesque Inc.). Cell lysates were resolved by sodium dodecyl sulfate-polyacrylamide gel electrophoresis (SDS-PAGE) and analyzed by western blot analysis as described previously [27]. For immunoprecipitation, cells were lysed in RIPA buffer $(50 \mathrm{mM}$ Tris-HCl, $\mathrm{pH} 7.5$, with
$150 \mathrm{mM} \mathrm{NaCl}, 1 \mathrm{mM}$ EDTA, $1 \% \mathrm{NP}-40$, and $0.5 \%$ sodium deoxycholate) containing a protease inhibitor cocktail (Nacalai Tesque Inc.), and immunoprecipitation was performed following standard protocols. Immunoprecipitates were resolved by SDS-PAGE and analyzed by western blotting.

The antibodies used for western blot analyses and immunoprecipitation in this study were anti-mouse Caspase-8 (ALX-804-447-C100, Enzo Life Science), antiRIPK1 (610458, BD Transduction Laboratories), antimouse RIPK3 (ADI-905-242-100, Enzo Life Science), anti-human Caspase-8 (M032-3, MBL), anti-Flag M2 (F3165, Sigma), anti-GFP (GF200, Nacalai Tesque Inc.), anti-MLKL (MABC604, MERCK MILLIPORE), anti-RAR (M-454, Santa Cruz), anti-Histone H3 (601901, BioLegend), anti-Caspase-3 (611049, BD Transduction Laboratories), anti-Caspase-7 (551238, BD Phamingen), antiRXR $\alpha$ (D-20, Santa Cruz), anti-TDG (GTX110473, Gene Tex), anti-CBP (451, Santa Cruz), and anti-Actin (MAB1501, MERCK MILLIPORE).

\section{Immunocytochemistry and whole-mount in situ hybridization}

Cells in chamber slides were fixed with $4 \%$ paraformaldehyde (Nacalai Tesque Inc.) in PBS for $15 \mathrm{~min}$ and permeabilized by three successive treatments with $0.3 \%$ Triton X-100 (Nacalai Tesque Inc.) in PBS for $2 \mathrm{~h}$. Cells were treated with primary antibodies for $12 \mathrm{~h}$ at $4{ }^{\circ} \mathrm{C}$, washed three times with $0.05 \%$ Tween-20 in PBS, and then treated with Alexa Fluor ${ }^{\circledR} 488$-conjugated anti-mouse IgG (Molecular Probes) for $1 \mathrm{~h}$. Fixed cells were washed three times with $0.05 \%$ Tween-20 in PBS and mounted with FluoroKEEPER Antifade Reagent with DAPI (Nacalai Tesque Inc.). Cells were analyzed under a confocal fluorescence microscope (OLYMPUS). The antibodies for immunocytochemistry used in this study were anti-Flag M2 (F3165, Sigma) and anti-Tuj1 (MAB1637, MECK MILLIPORE). Whole-mount in situ hybridization $(n>5)$ was performed as described previously [28, 29]. We did not use randomization.

\section{Dual-luciferase assay}

Tet-On shGFP or Tet-On shCasp 8 TT2 mouse ES cells transfected with $\mathrm{pRARE3-Luciferase}$ and pTK-Renilla luciferase were cultured with or without $1 \mu \mathrm{g} / \mathrm{ml}$ Dox for 5 days and then treated with or without $1 \mu \mathrm{M}$ RA for $24 \mathrm{~h}$. The dual-luciferase assay was performed using a dualluciferase assay kit (Promega) in accordance with the manufacturer's instructions. At least three biological experiments were carried out and data are presented as means $\pm \mathrm{SD}$. 


\section{Quantitative reverse transcription-polymerase chain reaction (qRT-PCR)}

Total RNA was extracted using Sepasol ${ }^{\circledR}$-RNA Super G (Nacalai Tesque Inc.) according to the manufacturer's instructions. The reverse transcription (RT) reaction was performed using a ReverTra Ace ${ }^{\circledast}$ qRT-PCR Master Mix (TOYOBO) according to the manufacturer's instructions. RT products were analyzed using a THUNDERBIRD ${ }^{\circledR}$ qPCR Mix (TOYOBO) and the StepOne real-time PCR system (Applied Biosystems) with the primer sets listed in Supplementary Table S2 according to the manufacturer's instructions. The expression level of each mRNA was normalized to that of mouse or human GAPDH. At least three biological experiments were carried out and data are presented as means \pm SD.

\section{Flow cytometric analysis}

HL60 cells expressing $\operatorname{sh} L a c Z$ or shCASP8 were cultured with or without $1 \mu \mathrm{M}$ RA for 3 days and then stained with FITC-conjugated anti-CD11b antibody (eBioscience) for $30 \mathrm{~min}$. Flow cytometric analysis was performed with a FACS canto2 (BD Biosciences).

\section{ChIP analysis}

ChIP analyses were performed as previously described [30]. In brief, quantitative PCR was performed using a THUNDERBIRD $^{\circledR}$ qPCR Mix (TOYOBO) and the StepOne realtime PCR system (Applied Biosystems) with the primer listed in Supplementary Table S3. The antibodies for ChIP analysis used in this study were anti-Flag M2 (F3165, Sigma), antiRAR (M-454, Santa Cruz), and anti-RIPK1 (610458, BD Transduction Laboratories). At least three biological experiments were carried out and data are presented as means \pm SD.

\section{Rescue experiments of Casp8 $8^{-1-}$ embryos using an RA antagonist}

BMS493 (Tocris Bioscience) in DMSO (100 mM) was diluted with olive oil to a final concentration of $3 \mu \mathrm{M}$ just before use. BMS493 (2.5 $\mu \mathrm{l} / \mathrm{g}$ of body weight; $7.5 \mathrm{pmol} / \mathrm{g}$ of body weight) was intraperitoneally injected into pregnant Casp $8^{+/-}$female mice intercrossed with $\operatorname{Casp}^{+/-}$male mice at E8.5, E9.5, and E10.5 after fertilization, and E11.5 Casp $8^{-1-}$ embryos were analyzed in comparison with Casp $8^{+/+}$littermates. We did not use randomization.

\section{In vitro binding assay of RIPKs and RARa}

Expression vectors of 3xFlag-RIPK1, 3xFlag-RIPK3, and HA-RAR $\alpha$ were transfected into HEK293T cells. Expressed recombinant proteins were purified by using
PURIFICATION KIT of DDDDK-tagged protein or HAtagged Protein (MBL). Recombinant proteins were incubated in interaction buffer, $(50 \mathrm{mM}$ Tris- $\mathrm{HCl}, \mathrm{pH} 8.0$ with $100 \mathrm{mM} \mathrm{NaCl}, 10 \mathrm{mM} \mathrm{MgCl} 2,10 \%$ glycerol, $0.3 \mathrm{mM}$ DTT, and $0.1 \%$ Nonidet P-40), and co-immunoprecipitation analysis was carried out.

\section{Generation of CRISPER/CAS9-mediated MIkI KO mice}

pX330-U6-Chimeric_BB-CBh-hSpCas9 was purchased from Addgene (Addgene plasmid 42230) [31]. Oligonucleotide for targeting sequence of mouse $M l k l$ exon4 was inserted into pX330-U6-Chimeric_BB-CBh-hSpCas9 using Bbs1 site. The plasmid was microinjected into zygotes, and genomic sequence of the born mice was determined. The used target sequence of CRISPR/CAS9 system is listed in Supplementary Table S4.

\section{Statistical analysis}

Quantitative data are presented as mean values \pm SD $(n=3)$ from more than three independent repetitions. Statistical comparisons between groups were carried out with the use of one-sided Student's $t$ test. $P$-values of $p<0.05\left(^{*}\right)$ and $p<0.01(* *)$ were regarded to be statistically significant, and $p$-value of $p<0.95$ was evaluated to be not significantly different (n.s.d.). We were not blinded to the group allocation during the experiment.

\section{Results}

\section{Knockdown of Casp8 expression evidently enhanced RA-induced cell differentiation}

The roles of Caspase- 8 on growth, viability and differentiation were investigated in mouse ES cells by utilizing a tetracycline/ doxycycline (Dox)-inducible short hairpin RNA (shRNA) expression (Tet-On) system [27, 32] specific for Casp8 (shCasp8) (Fig. 1a). While Casp8 expression was clearly downregulated by Dox treatment in ES cells with the Tet-On shCasp8 system (Tet-On shCasp8 ES cells) (Fig. 1b), significant effects on neither growth nor viability were observed in the ES cells after Dox treatment. However, 6-day RA treatment remarkably enhanced neural cell differentiation in embryoid body (EB) [33] derived from Casp8 knockdown ES (Casp8 KD ES) cells compared with control shGFP ES cells (Fig. 1c, d). Oct3/4, a marker of undifferentiated cells, was strongly downregulated (Fig. 1e), and the expression levels of neural differentiation markers, Nestin and Tujl, were upregulated in cells in RA-treated EBs derived from Casp 8 KD ES cells (Fig. 1f). Thus, knockdown of Casp 8 expression in ES cells markedly enhanced RA-induced neural differentiation. 
a

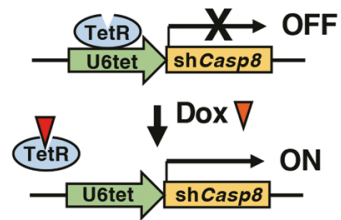

C

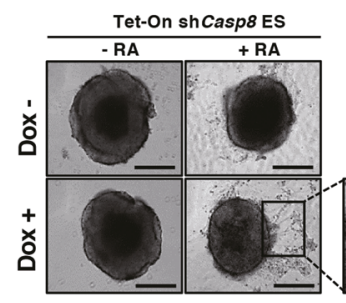

e

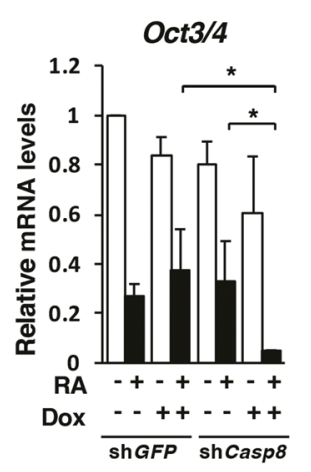

Fig. 1 Knockdown of Casp 8 expression in ES cells enhanced RAinduced cell differentiation. a Dox-inducible (Tet-On) shCasp8expression system. TetR, tetracycline repressor; and U6tet, mouse U6 promoter joining the tetracycline operator. b Validation of induced knockdown of Casp8 expression in Tet-On shCasp8 ES cells by western blot analysis after treatment with $1 \mu \mathrm{g} / \mathrm{ml}$ Dox for indicated days. Molecular weight markers are indicated $(\mathrm{kDa})$. Neuronal differentiation of Dox $(1 \mu \mathrm{g} / \mathrm{ml})$-treated or -untreated Tet-On shCasp8

\section{Knockdown of Casp8 or Fadd expression markedly enhanced RA signaling}

We then analyzed the expression levels of RA-specific target genes, Crabp2, Hoxb1, Cyp26al, and Rarb, which expressions were under the control of RARs and a $R A R E$ in the respective promoter regions of these genes [34-37]. qRT-PCR and dual-luciferase reporter analyses revealed that expression levels of all the RA-specific target genes and $R A R E$-dependent transcription of luciferase were dramatically elevated in Casp 8 KD ES cells treated with RA (Fig. 2a, b). Because the enhanced expressions of RAspecific target genes were observed by the treatment with even 10 nM RA (Supplementary Fig. S1a), Caspase-8 suppressed evident activation of RA signaling in a physiological condition $(\sim 25 \mathrm{nM})$ [38]. In addition, the expression levels of the RA-specific target genes were similarly elevated in ES cells expressing shCasp8 \#2, a different shRNA for mouse Casp8 (Supplementary Fig. S1b). While one of the RA-specific target genes, which expression were enhanced by knockdown of Casp8, was Rarb (RA receptor $\beta$ ), the expression levels of other types of RARs than Rarb [39, 40], were not influenced by knockdown of Casp8 (Supplementary Fig. S1c).

d
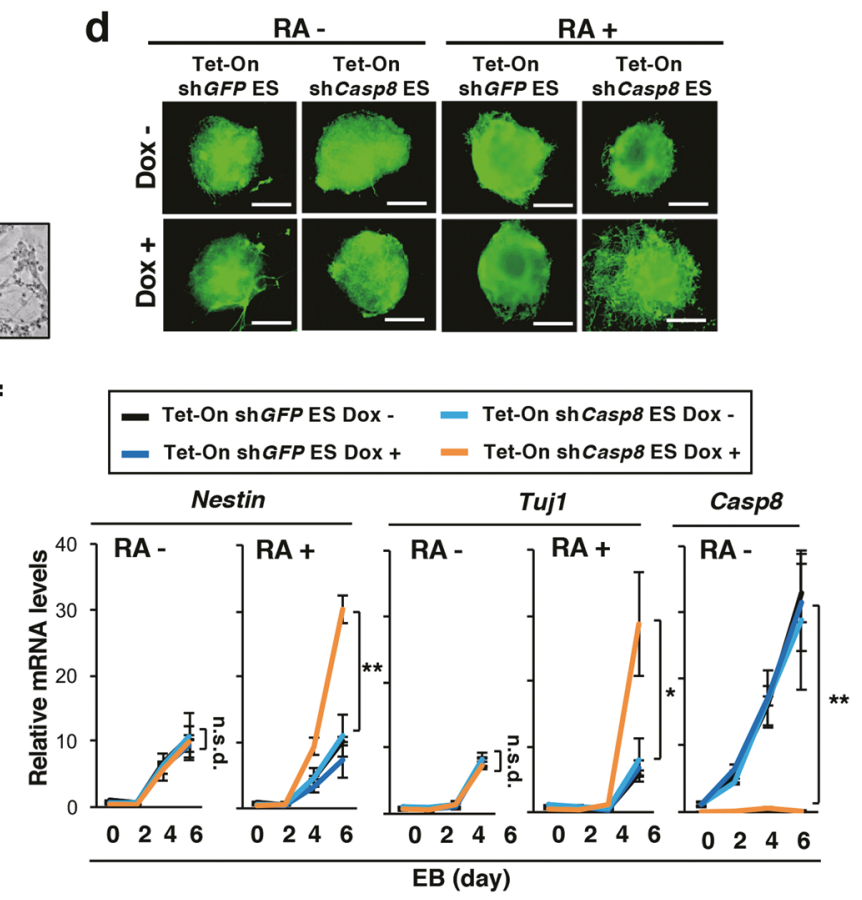

and Tet-On shGFP ES cells was analyzed by phase-contrast microscopy (c) or fluorescence microscopy (d) after 6-day formation of EBs. EBs were treated with or without $1 \mu \mathrm{M}$ RA for last 4 days. Scale bars, $200 \mu \mathrm{m}$. Cells were stained with anti-Tuj1 antibody in d. e qRT-PCR analysis of $O c t 3 / 4$ was carried out using EBs defined in c. f qRT-PCR analysis of Nestin, Tuj1, and Casp8 was carried out using ES cells at the indicated times after formation of EBs defined in c. ${ }^{* *} p<0.01$, $* p<0.05$ and n.s.d. (no significant difference: $p>0.95$ )

Thus, Caspase- 8 suppressed evident activation of RA signaling in ES cells through other mechanisms than a general increase of RARs expression.

The enhancement of RA signaling and RA-induced cell differentiation were induced by the inhibition of not only Casp8 expression in mouse embryonic carcinoma cell line P19 as well as mouse ES cells, but also Fadd expression in ES cells (Supplementary Fig. S2). In addition, knockdown of Caspase-8 (CASP8) expression in human RA-sensitive cancer cell lines, SK-N-SH and HL60, clearly enhanced RA signaling and RA-induced differentiation into neural cells expressing TUJ1 and monocytes expressing CDIlb, respectively (Supplementary Fig. S3). Thus, Caspase- 8 suppresses marked activation of RA signaling in not only mouse ES cells but also mouse embryonic carcinoma and human cancer cells.

Rescue experiments were performed using exogenous expression of knockdown-resistant wild-type (Wt) Casp8 in Casp 8 KD ES cells, and expression of Wt Casp 8 significantly inhibited the activation of RA signaling by Casp 8 knockdown (Supplementary Fig. 4). Then, similar rescue experiments were carried out using exogenous expression of knockdown-resistant two kinds of Casp 8 mutants, CS and DE [41]. The expression of DE Casp8, but not CS Casp8, 


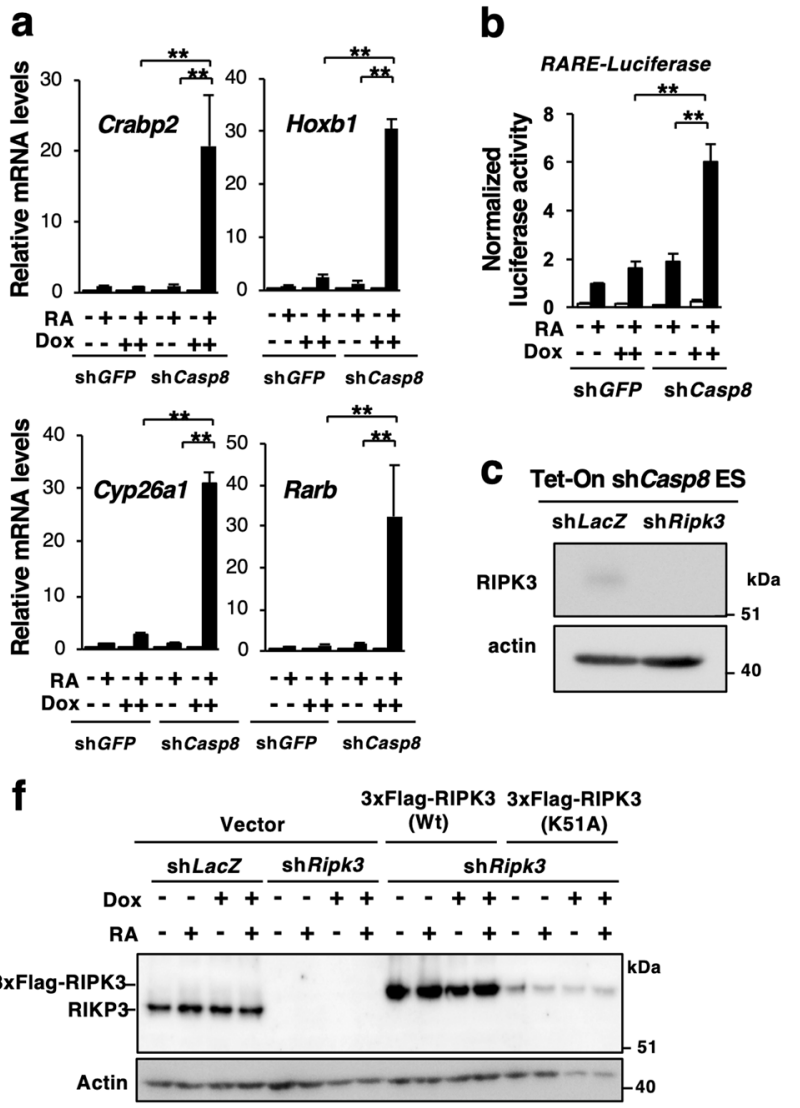

Fig. 2 Knockdown of Casp 8 expression in ES cells markedly enhanced RA signaling dependently on RIPK3. a Tet-On shCasp 8 and Tet-On shGFP ES cells were cultured for 4 days with or without $1 \mu \mathrm{g} / \mathrm{ml}$ Dox and then treated with or without $1 \mu \mathrm{M}$ RA for $24 \mathrm{~h}$ in the presence or absence of Dox. Subsequently, expression levels of RA-specific target genes, Crabp2, Hoxb1, Cyp26a1, and Rarb, were analyzed by qRTPCR. b Dual-luciferase assay for RARE was performed using ES cells defined in a. c Western blot analysis of RIPK3 expression was carried out in Tet-On shCasp8 ES cells expressing $\operatorname{shLacZ}$ or $\operatorname{shRipk3}$ in the absence of Dox. Actin was detected as a control. Molecular weight markers are indicated $(\mathrm{kDa})$. d qRT-PCR analysis of Nestin and Tuj1 expression was performed using EBs derived from Tet-On shCasp 8 ES

significantly inhibited the evident activation of RA signaling by Casp 8 knockdown in Tet-On shCasp 8 P19 cells (Supplementary Fig. S4). These results showed that protease activity of procaspase- 8 was indispensable but cleavageassociated activation of procaspase- 8 was not necessary for inhibition of the marked activation of RA signaling.

\section{RIPK1 and RIPK3, but not MLKL, were involved in Casp8 knockdown-induced enhancement of RA signaling}

Caspase- 8 and FADD inhibit necroptosis mediated by RIPK1， RIPK3, and MLKL [10-14]. Downregulated expression of Ripk3 canceled the enhancement of RAinduced differentiation in Casp8 KD ES cells as well as the enhancement of RA-specific target genes expressions and d
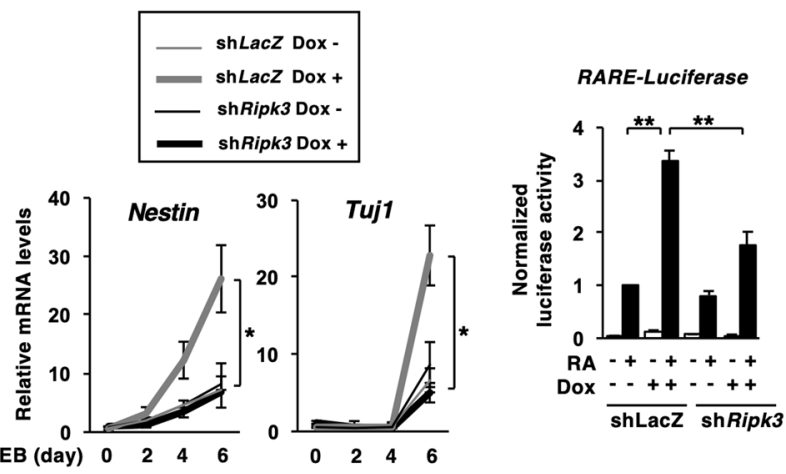

g
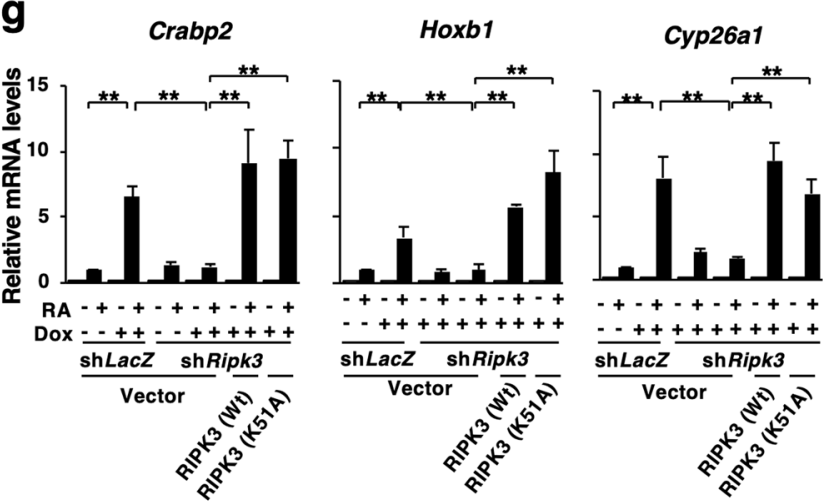

cells expressing $\operatorname{sh} L a c Z$ or shRipk 3 after 6 days formation of EBs in the presence or absence of $1 \mu \mathrm{g} / \mathrm{ml}$ Dox. EBs were treated with $1 \mu \mathrm{M}$ RA for last 4 days. e Dual-luciferase assay for RARE was carried out using TetOn shCasp8 ES cells expressing shLacZ or shRipk3 after treatment with or without $1 \mu \mathrm{M}$ RA for $24 \mathrm{~h}$ in the presence or absence of $1 \mu \mathrm{g} / \mathrm{ml}$ Dox.

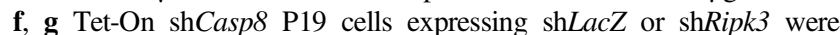
infected with lentiviral vectors carrying 3xFlag-Wt Ripk3 or K51A Ripk3. These cells were cultured with or without $1 \mu \mathrm{g} / \mathrm{ml}$ Dox for 5 days, and then treated with or without $1 \mu \mathrm{M}$ RA for $24 \mathrm{~h}$ in the presence or absence of Dox. Subsequently, western blot analysis for RIPK3 (f) and qRT-PCR analysis for RA-inducible genes (g) were carried out. Vector, an empty vector. $* * p<0.01$ and $* p<0.05$

RARE-dependent transcription of luciferase in Casp8 KD P19 cells (Fig. 2c-g). In addition, Ripkl but not MLKL were involved in the enhancement of RA signaling in Casp8 KD P19 cells (Fig. 3a-d). Furthermore, treatment of SK-N-SH and HL60 cells with a human MLKL-specific inhibitor, necrosulfonamide (NSA) [14], failed to inhibit the Casp8 knockdown-induced enhancement of RA responses (Fig. 3e, f). In shRipk3-expressing Casp8 KD P19 cells, Casp 8 knockdown-induced enhancement of RA signaling was restored by exogenous expression of knockdown-resistant Wt Ripk3 and a kinase-negative mutant, K51A Ripk3 [13] (Fig. 2f, g). Treatment of Casp8 KD P19 cells with a kinase inhibitor of RIPK1, Nec-1 [42], did not inhibit the Casp8 knockdown-induced enhancement of RA signaling (Fig. 3g). These results indicated that both RIPK1 and RIPK3 but neither MLKL 

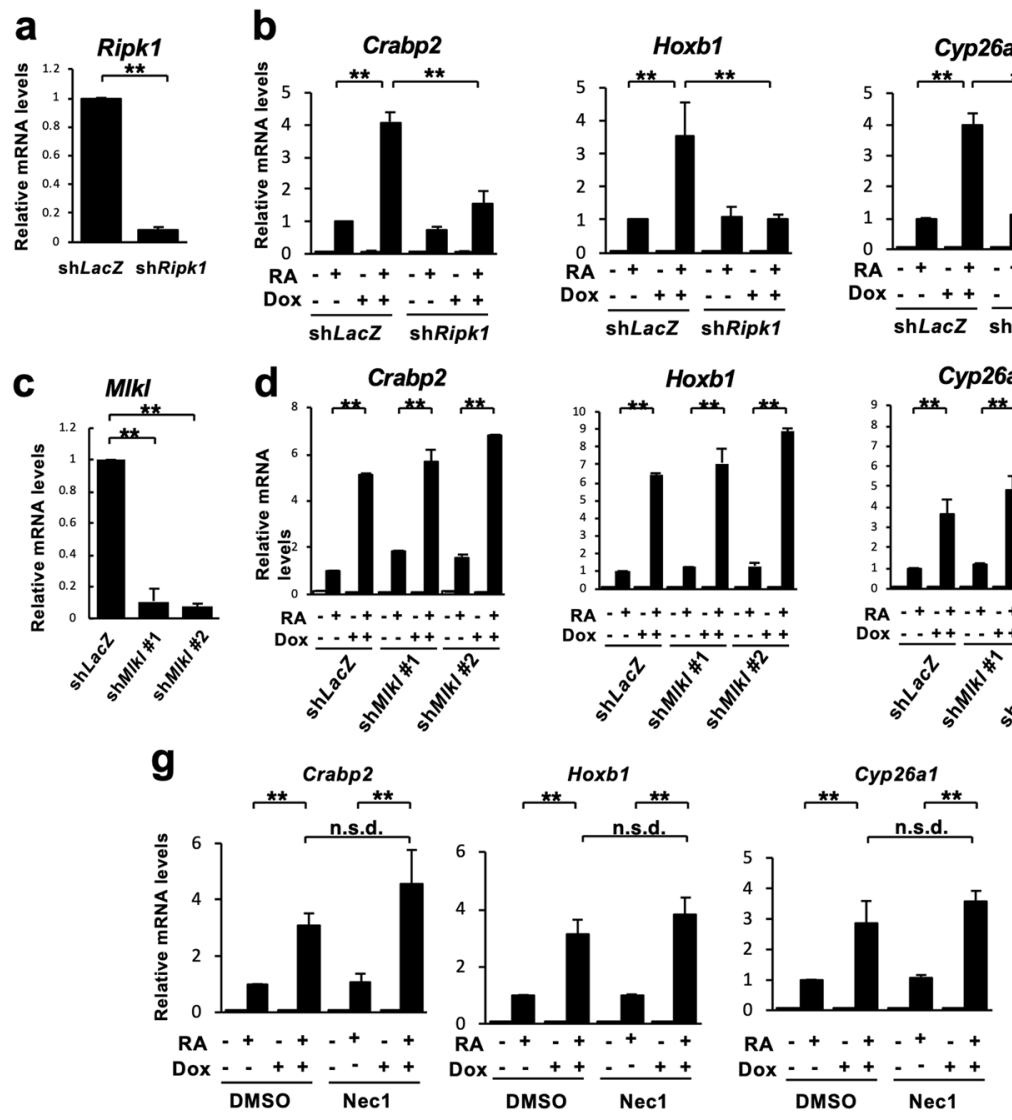

Fig. 3 RIPK1 but not MLKL is involved in the activation of RA signaling. a Expression levels of Ripk1 were analyzed by qRT-PCR using Tet-On shCasp8 P19 cells expressing shLacZ or shRipk1. b P19 cells defined in a were cultured for 4 days with or without $1 \mu \mathrm{g} / \mathrm{ml}$ Dox and then treated with or without $1 \mu \mathrm{M}$ RA for $24 \mathrm{~h}$ in the presence or absence of Dox. Subsequently, qRT-PCR analysis of RA-induced genes, Crabp2, $H o x b 1$, and Cyp26al, was performed. c Expression levels of Mlkl were analyzed by qRT-PCR using Tet-On shCasp 8 P19 cells expressing $\mathrm{sh} L a c Z$ or shMlkl. Two shRNAs targeting different nucleotide sequences

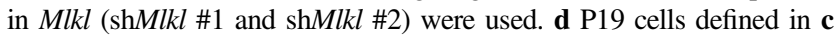

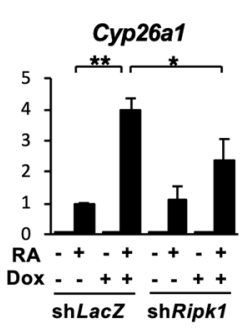

e

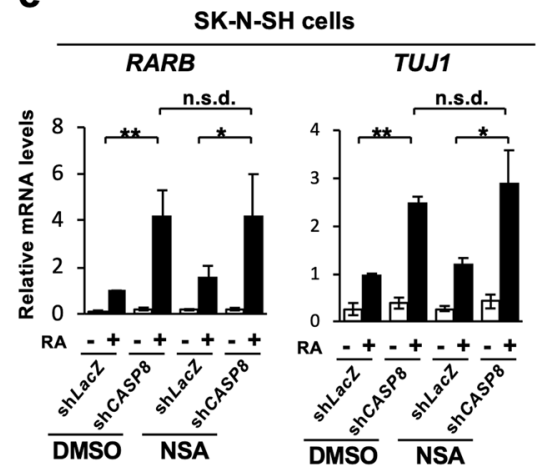

f

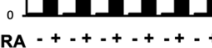

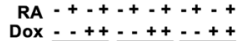
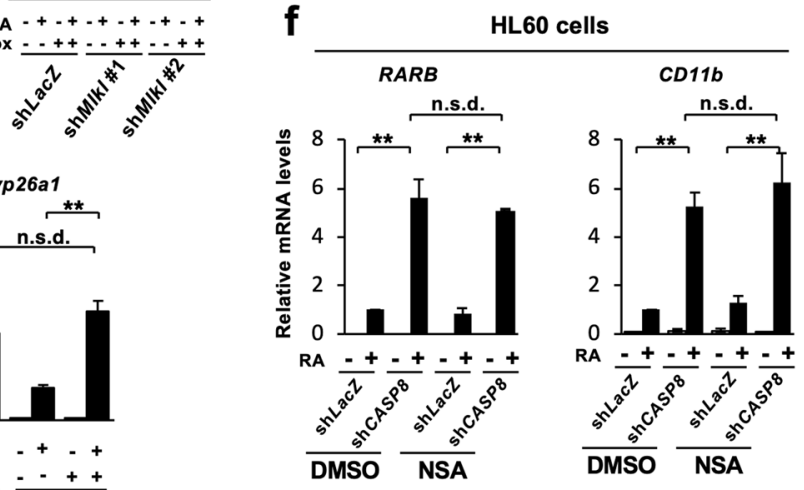

nor their kinase activities played an essential role in the enhancement of RA signaling induced by the knockdown of Casp 8 expression.

RA treatment is well known to induce apoptosis. The expression levels of RA-specific target genes were not affected by double knockdown of Casp3 and Casp7, which inhibited apoptosis, in either Casp8-expressing or Casp8 KD P19 cells in the presence or absence of RA (Supplementary Fig. S5). These results suggested that the enhancement of RA signaling by Casp 8 knockdown was due to neither suppression nor enhancement of apoptosis.

\section{Knockdown of Casp8 expression sensitized cells in EBs to RA-induced necroptosis}

Two-day RA treatment of EBs derived from Casp8 KD ES cells expressing shCasp 8 or shCasp 8 \#2 were smaller than were analyzed by qRT-PCR as described in b. qRT-PCR analysis of $T U J 1$ and $R A R B$, and $C D 11 b$ and RARB was carried out using SK-N-SH cells (e) and HL60 cells (f), respectively, expressing shLacZ or shCASP8 after treatment with DMSO or $10 \mu \mathrm{M}$ NSA for $48 \mathrm{~h}$ together with or without $1 \mu \mathrm{M}$ RA for last $24 \mathrm{~h}$ in the presence of DMSO or $10 \mu \mathrm{M}$ NSA. g qRT-PCR analysis of RA-induced genes, Crabp2, Hoxb1, and Cyp26al, was performed using Dox $(1 \mu \mathrm{g} / \mathrm{ml})$-treated or -untreated TetOn shCasp8 P19 cells cultured with or without $1 \mu \mathrm{M}$ RA for $24 \mathrm{~h}$ in the presence of DMSO or $30 \mu \mathrm{M} \mathrm{Nec}-1 . * * p<0.01, * p<0.05$ and n.s.d. (no significant difference: $p>0.95$ )

EBs from Tet-On shCasp8 ES cells treated with Dox but not with RA or those treated with RA but not with Dox (Fig. 4a, b and Supplementary Fig. S6a). We then analyzed whether cell death was induced in the EBs by LDH release assay, indicating that cell death was clearly induced in the RAtreated EBs derived from Casp8 KD ES cells (Fig. 4c). The cell death was inhibited by treatment with Nec-1 (Fig. 4a-c). Knockdown of Ripk3 expression, which inhibited both necroptosis and the marked enhancement of RA signaling, strongly inhibited RA-induced cell death in Casp8 KD ES cells (Fig. 4c). RA-induced cell death in the EBs was inhibited by exogenous expression of Wt Casp8 and DE Casp8 but not CS Casp8 (Supplementary Fig. S6b, c), indicating that protease activity of procaspase- 8 regulated RA-induced cell death as well as RA signaling. RAinduced cell death was not inhibited in EBs derived from Casp 8 KD ES cells by the treatment with zVAD-fmk, while 
a

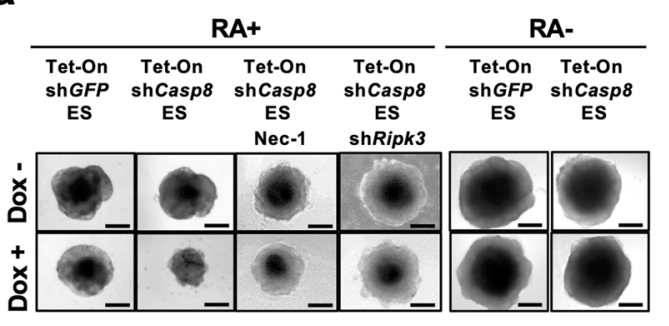

b

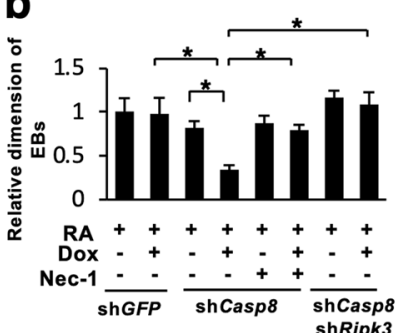

C

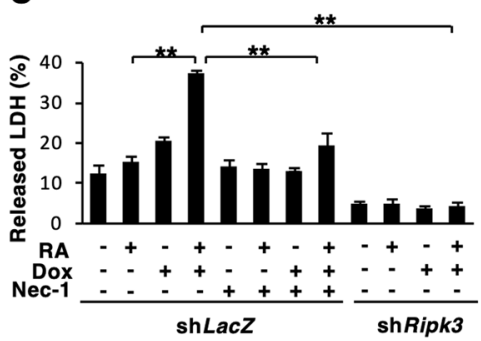

d

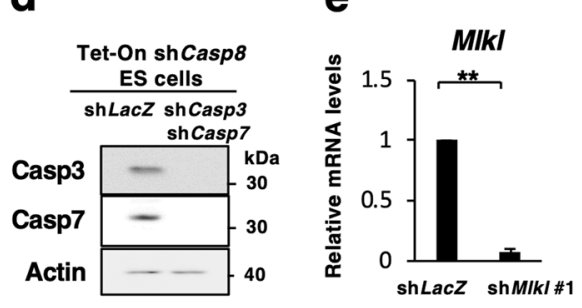

f

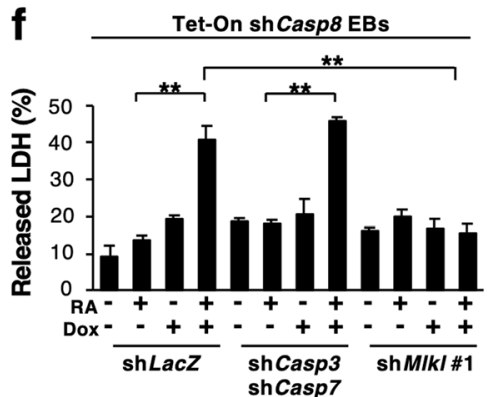

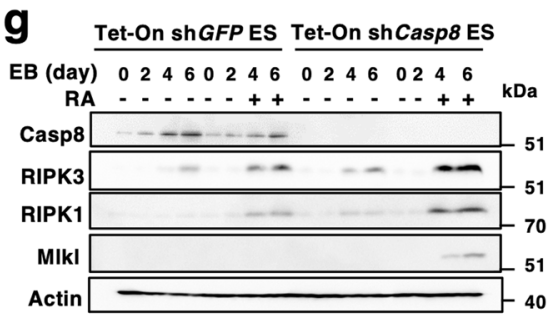

h

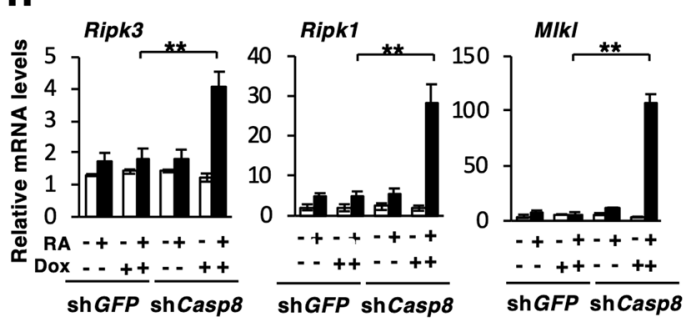

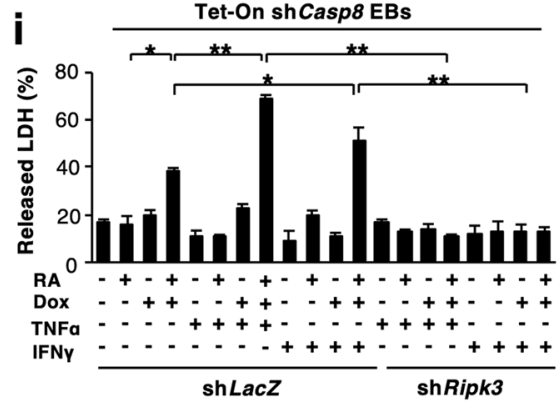

Fig. 4 Knockdown of Casp 8 expression in ES cells enhanced RAinduced necroptosis in EBs. a Dox $(1 \mu \mathrm{g} / \mathrm{ml})$-treated or -untreated TetOn shCasp8 or Tet-On shGFP ES cells expressing or not expressing shRipk3 were analyzed by phase-contrast microscopy after 4 days formation of EBs. EBs were treated with or without $1 \mu \mathrm{M}$ RA and $30 \mu \mathrm{M}$ Nec-1 for last 2 days. Scale bars, $200 \mu \mathrm{m}$. b Relative diameters of EBs defined in a were measured under phase-contrast microscopy. $n=10$. c Cell death was quantified by a lactate dehydrogenase (LDH) release assay after 4 days of formation of EBs derived from Tet-On shCasp8 ES cells expressing shRipk3 or shLacZ. EBs were treated with or without $1 \mu \mathrm{M}$ RA and $30 \mu \mathrm{M} \mathrm{Nec}-1$ for last 2 days. ES cells or EBs were cultured with $1 \mu \mathrm{g} / \mathrm{ml}$ Dox throughout the experiments. d Tet-On shCasp 8 ES cells expressing shLacZ or both shCasp 3 and shCasp 7 were subjected to western blot analysis using anti-Caspase-3 or anti-Caspase-7 antibodies. Actin was detected as a control. e Tet-On shCasp 8 ES cells expressing $\operatorname{shLacZ}$ or $\operatorname{sh} M l k l \# 1$ were subjected to
qRT-PCR analysis for Mlkl. f Cell death was quantified by LDH release assay after 4 days formation of EBs derived from ES cells defined in $\mathbf{d}$ and $\mathbf{e}$. EBs were treated with or without $1 \mu \mathrm{M}$ RA for last 2 days. Casp 8 KD ES cells or EBs were treated with $1 \mu \mathrm{g} / \mathrm{ml}$ Dox throughout the experiments. g Western blot analysis of Casp8, Ripk1, Ripk3, and Mlkl was performed using Tet-On shGFP and Tet-On shCasp8 ES cells after 0-6 days of formation of EBs in the presence or absence of $1 \mu \mathrm{g} / \mathrm{ml}$ Dox. EBs were cultured with or without $1 \mu \mathrm{M} \mathrm{RA}$ after 3 days of formation of EBs. Actin was detected as a control. Molecular weight markers are indicated $(\mathrm{kDa})$. h qRT-PCR analysis of Ripk1, Ripk3, and Mlkl was performed using ES cells defined in $\mathbf{g}$ before and after 6 days of EBs formation. i Cell death was quantified by LDH release assay after 4 days of formation of EBs described in $\mathbf{c}$. EBs were treated with or without $1 \mu \mathrm{M}$ RA for last 2 days in the presence or absence of $10 \mathrm{ng} / \mathrm{ml} \mathrm{TNF} \alpha$ or $10 \mathrm{ng} / \mathrm{ml} \mathrm{IFN} \gamma$. ${ }^{* *} p<0.01$ and $* p<0.05$.

Then the expression levels of Ripkl, Ripk3, and Mlkl in EBs derived from Casp 8 KD ES cells were quantified. During RA-induced differentiation, expression levels of Ripk1, Ripk3, and Mlkl in EBs derived from Casp8 KD ES cells were remarkably increased in both mRNA and protein levels (Fig. 4g, h). In addition, the expression level of tumor necrosis factor $\alpha$ (TNF $\alpha)$, but not interferon $\alpha$ (IFN $\alpha)$, IFN $\beta$ or IFN $\gamma$, increased after RA treatment in EBs derived from Casp8 KD ES cells (Supplementary Fig, S7). Importantly, TNF $\alpha$ and IFN $\gamma$ 
enhanced necroptosis in RA-treated but not in RAuntreated EBs derived from Casp 8 KD ES cells (Fig. 4i). Thus, the enhancement of RA signaling by Casp8 knockdown would sensitize Casp $8 \mathrm{KD}$ cells in EBs to necroptosis through the upregulated expressions of Ripk1, Ripk3, Mlkl, and TNF $\alpha$.

\section{Knockdown of Casp8 expression induced nuclear translocation of RIPK1 and RIPK3 to form a complex with RARs}

Treatment of Casp8-expressing P19 cells with Leptomycin B (LMB), an inhibitor of nuclear export of proteins [43], converted the subcellular localization of RIPK3 from the cytoplasm to the nucleus (Fig. 5a). LMB treatment also induced promotion of RA signaling in a RIPK3-dependent manner (Fig. 5b), suggesting that RIPK3 in the nucleus might enhance RA signaling. In addition, knockdown of Casp8 expression converted subcellular localization of RIPK3 from the cytoplasm to

a
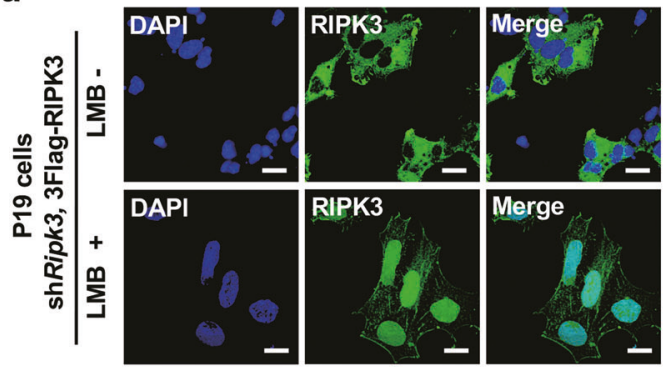

b

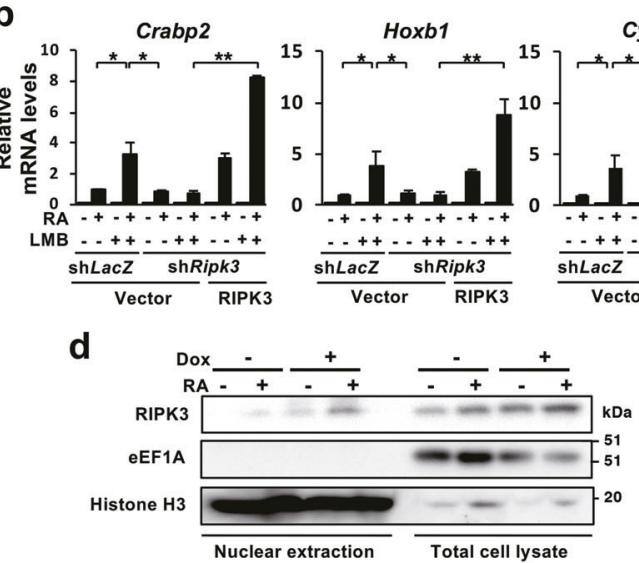

Fig. 5 Knockdown of Casp 8 expression induced nuclear translocation of RIPK3 to enhance RA signaling. a P19 cells expressing shRipk3 and shRipk3-resistant 3xFlag-Ripk3 were treated with or without $2 \mathrm{ng} / \mathrm{ml} \mathrm{LMB}$ for $24 \mathrm{~h}$. Subsequently, subcellular localization of 3xFlag-RIPK3 was analyzed by confocal fluorescence microscopy after staining with Alexa Fluor ${ }^{\circledR}$ 488-anti-Flag antibody and DAPI. Scale bars, $20 \mu \mathrm{m}$. b P19 cells defined in a and expressing $\operatorname{sh} L a c Z$ were subjected to qRT-PCR analysis of RA-specific target genes, Crabp2, Hoxb1, and Cyp26a1, after treatment with or without $1 \mu \mathrm{M}$ RA and $2 \mathrm{ng} / \mathrm{ml} \mathrm{LMB}$ for $24 \mathrm{~h}$. Vector, an empty vector. c Tet-On shCasp8 P19 cells and Tet-On shLacZ P19 cells expressing shRipk3 the cytoplasm and nucleus (Fig. 5c, d). Caspase-8 seemed to suppress nuclear translocation of RIPK3, and intranuclear RIPK3 might play an important role in the enhanced activation of RA signaling in the absence of Caspase-8.

Subcellular localization of exogenously expressed RIPK1 and RIPK3 in P19 cells was also converted from the cytoplasm to the cytoplasm and nucleus by overexpression of RAR $\alpha$, which is a nuclear protein (Fig. 6a-c). Overexpressed RAR $\alpha$ seemed to retain RIPK1 and RIPK3 in the nucleus. In co-immunoprecipitation experiments, exogenously expressed RIPK3 interacted with exogenously expressed RAR $\alpha$ in HEK293T cell extracts (Fig. 6d), and immunoprecipitation of exogenous Flag-tagged RIPK3 with anti-Flag antibody co-precipitated endogenous RAR $\alpha$ from extracts of Casp 8 KD ES cells (Fig. 6e). Importantly, endogenous RIPK1 and RIPK3 were coimmunoprecipitated with endogenous RAR $\alpha$ from extracts of Casp8 KD ES cells, and the interactions of RAR $\alpha$ to both RIPK1 and RIPK3 were shown to be enhanced by

\section{C}

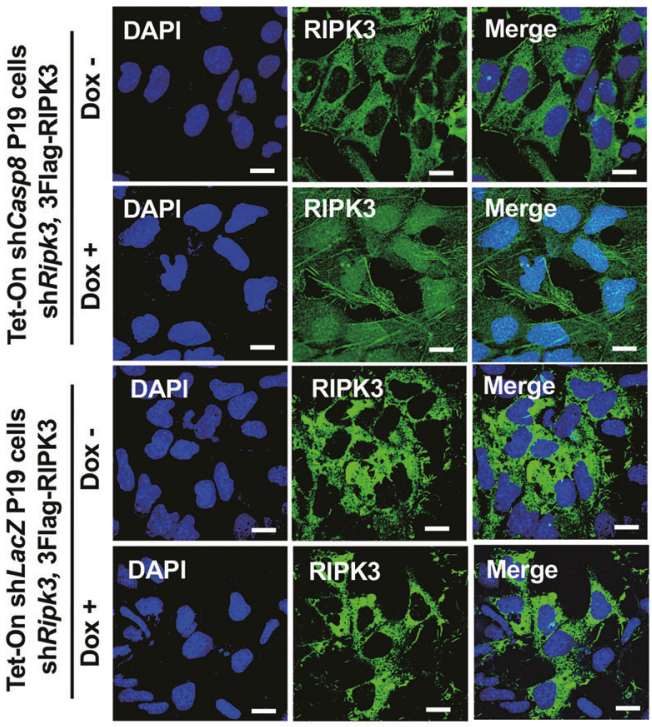

and shRipk3-resistant 3xFlag-Wt Ripk3 were cultured with or without $1 \mu \mathrm{g} / \mathrm{ml}$ Dox for 4 days. Subsequently, subcellular localization of 3xFlag-RIPK3 was analyzed by confocal fluorescence microscopy after staining with Alexa Fluor ${ }^{\circledR}$ 488-anti-Flag antibody and DAPI. Scale bars, $20 \mu \mathrm{m}$. d Western blot analysis of endogenous RIPK3 from nuclear fractions and total cell lysates was carried out using Tet-On shCasp8 ES cells cultured with or without $1 \mu \mathrm{g} / \mathrm{ml}$ Dox for 5 days. Cells were treated with or without $1 \mu \mathrm{M}$ RA for last $24 \mathrm{~h}$. Cytoplasmic eEF1A1 and nuclear Histone H3 were simultaneously analyzed. Molecular weight markers are indicated $(\mathrm{kDa}) . * * p<0.01$ and $* p<0.05$ 
a

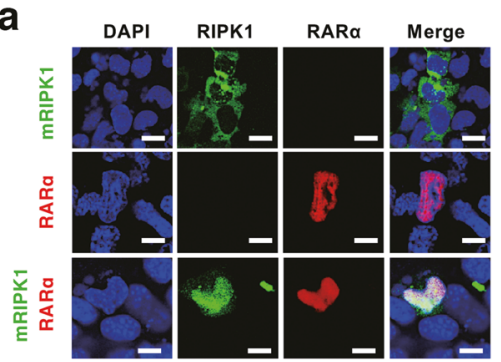

d

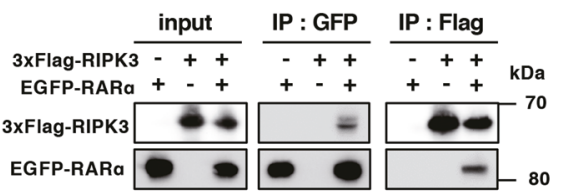

b

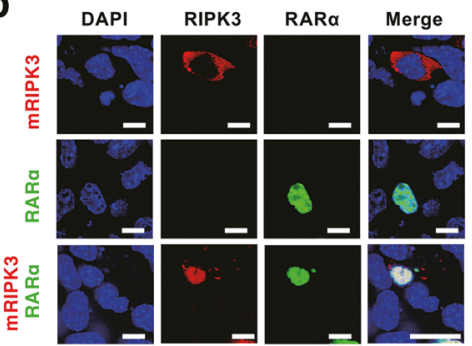

e

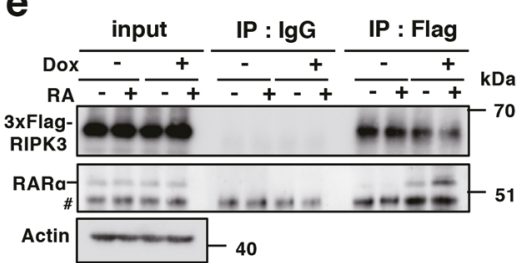

C

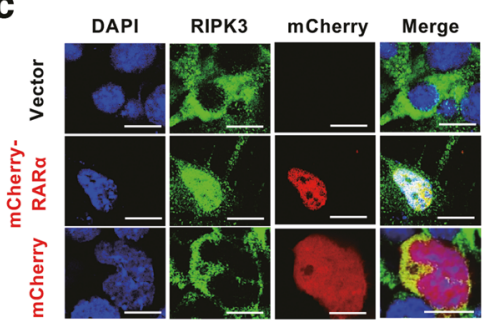

Fig. 6 RIPK1 and RIPK3 interacted with RAR $\alpha$. P19 cells were transfected with expression vectors encoding EGFP-RIPK1 and/or mCherry-RAR $\alpha$ (a), or mCherry-RIPK3 and/or EGFP-RAR $\alpha$ (b). Cells were cultured for $48 \mathrm{~h}$, and subcellular localization of these proteins was analyzed by confocal fluorescence microscopy after staining with DAPI. Scale bars, $20 \mu \mathrm{m}$. c P19 cells expressing shRipk3 and shRipk3-resistant 3xFlag-Ripk3 were transfected with an expression vector encoding mCherry-RAR $\alpha$ or mCherry, and cultured for $48 \mathrm{~h}$. Then, subcellular localization of mCherry-RAR $\alpha$ or mCherry was analyzed by fluorescence microscopy after staining with DAPI. Scale bar, $20 \mu \mathrm{m}$. d Lysates of HEK293T cells transiently expressing 3xFlag-tagged RIPK3 and/or EGFP-RAR $\alpha$ were subjected

RA treatment (Fig. 6f). Thus, knockdown of Casp8 expression induced nuclear localization of RIPK1 and RIPK3, and RIPK1 and RIPK3 interacted with RAR $\alpha$ in the nucleus.

Co-immunoprecipitation analyses using various deletion mutants of RAR $\alpha$ and RIPK3 indicated that RAR $\alpha$ and RIPK3 interacted through the ligand-binding domain (LBD) of RAR $\alpha$ and the protein kinase domain (PKD) of RIPK3 (Supplementary Fig. S8a-d). In vitro binding assay also revealed that both RIPK1 and RIPK3 could directly interact with RAR $\alpha$ (Supplementary Fig. S8e, f). Typical nuclear localization signals (NLSs) were found in RIP homotypic interaction motif (RHIM) domains of both RIPK1 and RIPK3 (Supplementary Fig. S9). RHIM domains of RIPK1 and RIPK3 were localized in nucleus and these RHIM domains seemed to co-localize with RAR $\alpha$ in the nucleus (Supplementary Fig. S10a, b). Moreover, an AAAA mutation in RHIM domains of RIPKs restricted the nuclear localization of RIPKs (Supplementary Fig. S10a, b). In coimmunoprecipitation experiments revealed that RHIM domain of RIPK3 was important for interaction between RIPK3 and RAR $\alpha$ (Supplementary Fig. S10c, d). In shRipk3expressing Casp8 KD P19 cells, Casp 8 knockdown-induced enhancement of RA signaling was completely suppressed by exogenous expression of knockdown-resistant RHIM domain AAAA mutant RIPK3 (Supplementary Fig. S10e). to immunoprecipitation (IP) with anti-Flag antibody (Flag) or anti-GFP antibody (GFP), and analyzed by western blotting with antiFlag antibody or anti-GFP antibody. Total cell lysates (input) were also analyzed. Molecular weight markers are indicated $(\mathrm{kDa})$. Dox $(1 \mu \mathrm{g} / \mathrm{ml})$-treated or -untreated Tet-On shCasp 8 ES cells expressing (e) or not expressing (f) shRipk3 and shRipk3-resistant 3xFlag-Ripk3 were analyzed after 4 days formation of EBs. EBs were treated with or without $1 \mu \mathrm{M}$ RA for last 2 days. Western blot analysis was carried out for immunoprecipitates with control $\operatorname{IgG}(\operatorname{IgG})$ or ant-Flag antibody (Flag) (d), and with control IgG or anti-RAR $\alpha$. Total cell lysates (Input) were also analyzed. Hash indicates nonspecific bands and double hashindicates IgG-derived bands

Taken together, RIPK1 and RIPK3 independently and directly bind to LBD of RAR $\alpha$ through their PKDs, and RHIM domains of RIPKs containing NLS are essential for both binding of RIPK3 to RAR $\alpha$ and Casp 8 knockdowninduced enhancement of RA signaling.

\section{RIPK1 and RIPK3 in the transcriptional coactivator complex has a functional role to enhance RA- dependent transcription}

To clarify whether the complex of RARs with RIPK1 and RIPK3 functions in RA-dependent transcription, chromatin immunoprecipitation (ChIP) analysis was carried out in Casp8 KD ES cells. RA treatment notably enhanced binding of endogenous RIPK1 to RARE of an RA-inducible gene, Rarb, specifically in the absence of Casp 8 expression (Fig. 7a). RA treatment also enhanced the binding of exogenously expressed $\mathrm{Wt}$ and a kinase-negative mutant, K51A, RIPK3, but not of RIPK3 with the RHIM AAAA mutant, to RARE of an RA-inducible gene, Cyp26al, in the absence of endogenous Ripk3 and Casp8 expressions (Fig. 7b). Furthermore, knockdown of Casp 8 significantly enhanced RA-induced binding of RARs to RARE dependently on expression of either RIPK3 or RHIM domain of RIPK3 but independently on the kinase activity of RIPK3 (Fig. 7c). Taken together, RARs, bound to RIPK1 and 
a

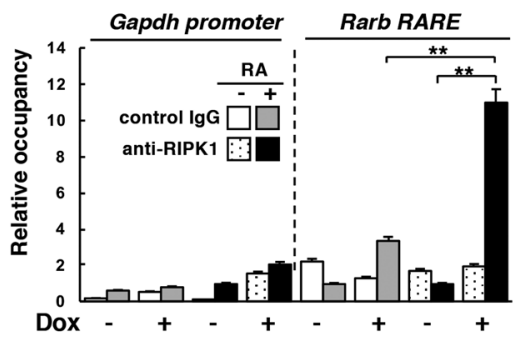

C

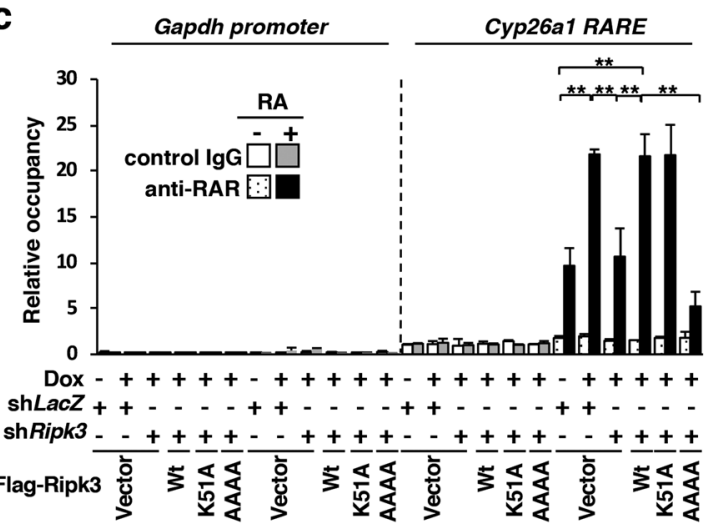

Fig. 7 RA treatment notably enhanced binding of not only RARs but also RIPK1 and RIPK3 to RAREs of RA-inducible genes in the absence of Casp 8 expression. a Tet-On shCasp 8 ES cells were cultured with or without $1 \mu \mathrm{g} / \mathrm{ml}$ Dox for 4 days and then treated with or without $1 \mu \mathrm{M}$ RA for $24 \mathrm{~h}$ in the presence or absence of Dox. Subsequently, ChIP analysis for the Rarb-specific RARE or Gapdh promoter region using an anti-RIPK1 antibody was carried out. Tet-On shCasp8 P19 cells expressing shRipk3 (shRipk3+) or shLacZ (shRipk3-) together with or without the expression of shRipk3-resistant 3xFlag-Wt RIPK3, kinase-negative 551 A mutant RIPK3, or RHIM AAAA mutant RIPK3 were treated with or without $1 \mu \mathrm{M}$ RA for $24 \mathrm{~h}$

RIPK3 in Casp8 KD cells, showed much stronger binding activity to RARE in the presence of RA than RARs without RIPK1 and RIPK3.

Knockdown of RXR $\alpha$, TDG, p300, and CBP, all of which were reported to form a transcriptional coactivator complex with RAR on RAREs and to enhance RA signaling [44-46], inhibited the Casp8 knockdown-induced enhancement of RA signaling (Supplementary Fig. S11) and formed a complex with RIPK3 in the nucleus of RAtreated Casp8 KD EBs (Fig. 7d). This transcriptional coactivator complex formation with RIPK1 and RIPK3 would play an important role in the enhancement of RAdependent transcription.

\section{RA signaling was enhanced in Caspase-8-deficient mouse embryos regardless of $\mathrm{Mlkl}$ expression}

Casp8-deficient $\left(\right.$ Casp $\left.^{-/-}\right)$mouse embryos die at E11.5 with associated abnormal yolk sac vascularization, heart development, and neural tube formation $[9,15]$. In mouse
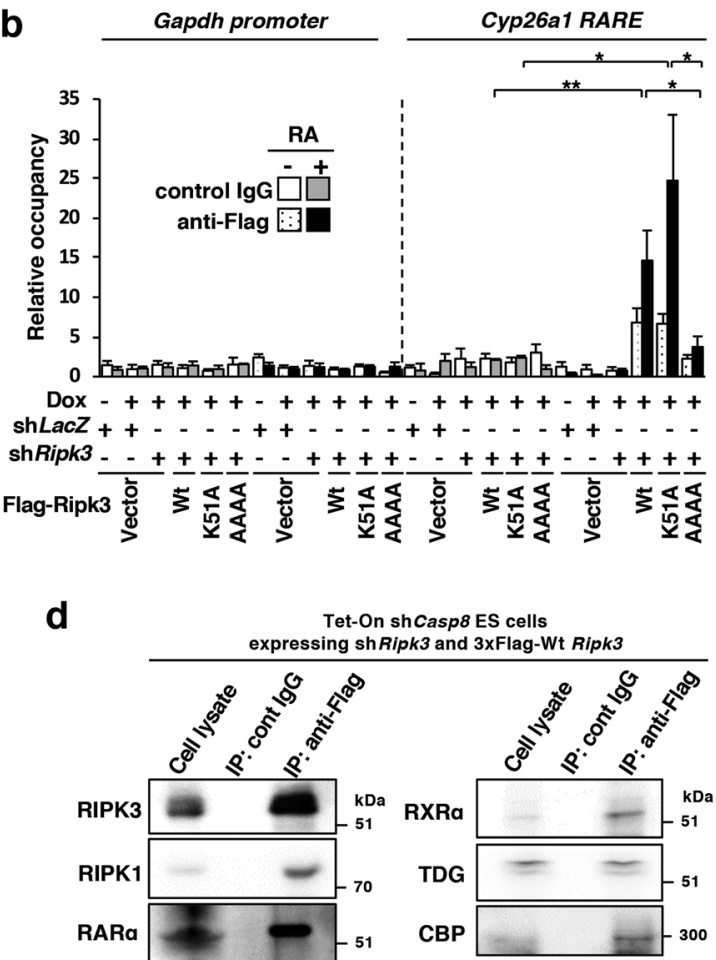

in the presence or absence of $1 \mu \mathrm{g} / \mathrm{ml}$ Dox, and subjected to ChIP analysis for the Cyr26al-specific RARE or Gapdh promoter region using anti-Flag antibody or control IgG (b), or using anti-RAR antibody or control IgG (c). Vector, an empty vector. d Dox $(1 \mu \mathrm{g} / \mathrm{ml})-$ treated Tet-On shCasp8 ES cells expressing shRipk3 and shRipk3resistant 3xFlag-Wt RIPK3 were subjected to immunoprecipitation (IP) after 4 days formation of EBs. EBs were treated with $1 \mu \mathrm{M}$ RA for last 2 days. Immunoprecipitates with control IgG and ant-Flag antibodies were subjected to western blot analysis using indicated antibodies. Molecular weight markers are indicated $(\mathrm{kDa}) . * * p<0.01$ and $* p<0.05$

embryonic fibroblasts (MEFs) from $\mathrm{Casp}^{-/-}$mice (Fig. 8a), RA-induced gene expression as well as RAREdependent transcription of luciferase was enhanced, compared with $\mathrm{Casp}^{+/+}$MEFs (Fig. 8b, c). We also detected upregulated transcription of RA-induced genes in $\operatorname{Casp8^{-/}}$ whole embryos at E10.5 by qRT-PCR and in situ hybridization analyses (Fig. 8d, e). The upregulation was prominent in the embryo at E11.5 specifically in heart, aortagonad-mesonephros (AGM) and neural tube, all of which were abnormal in Casp $8^{-/-}$embryos (Fig. 8e-g). Thus, RA signaling was enhanced in $\operatorname{Casp}^{-/-}$embryos as well as Casp8 KD cells.

A chemical inhibitor of RA signaling, BMS493 [47], was intraperitoneally injected into the pregnant Casp 8 heterozygous $\left(\mathrm{Casp}^{+/-}\right)$female mice intercrossed with $\mathrm{Casp} 8^{+-}$ male mice (Supplementary Fig. S12a). The upregulated expression of RA-specific target genes in Casp $^{-1-}$ embryos was partly but significantly suppressed by treatment with BMS493 (Supplementary Fig. S12b). BMS493treated Casp8-deficient embryos were observed to be viable 
a

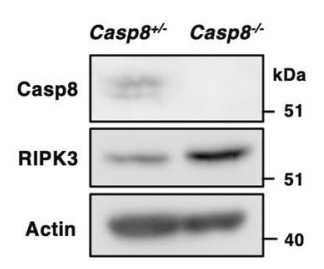

e
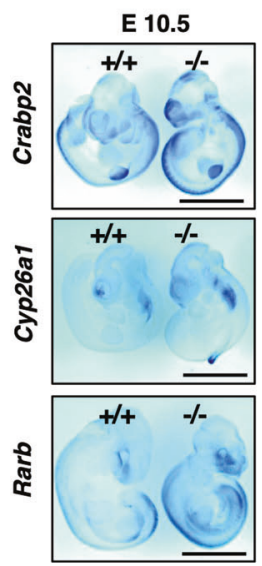

b

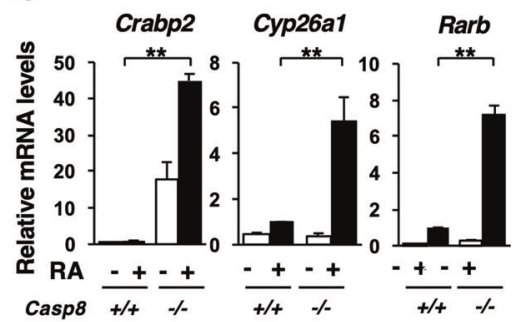

C

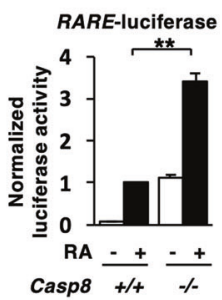

d

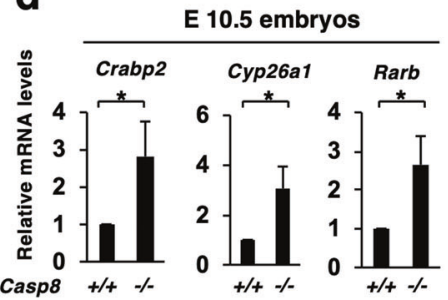

\section{$\mathbf{g}$}

E 11.5 neural tube

f E 11.5 Casp8embryo

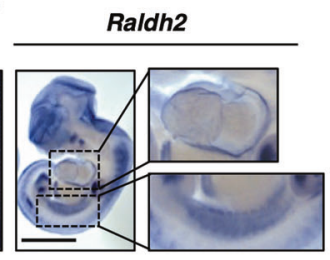

$\mathbf{h}$
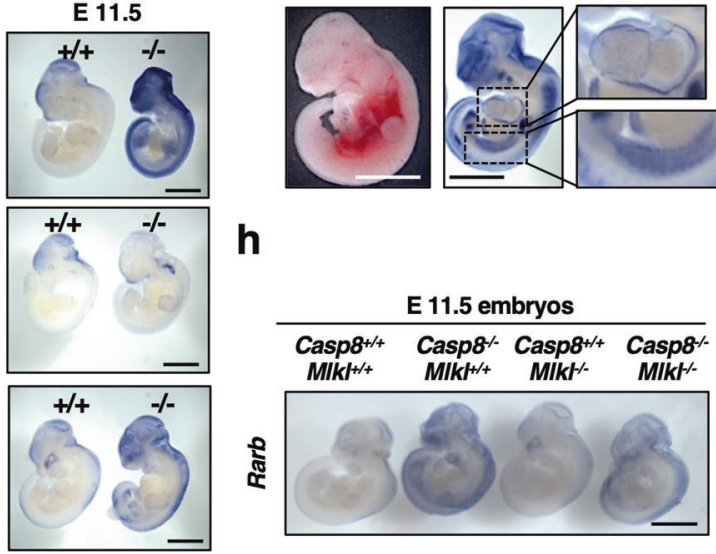

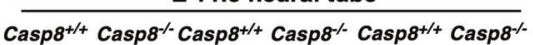
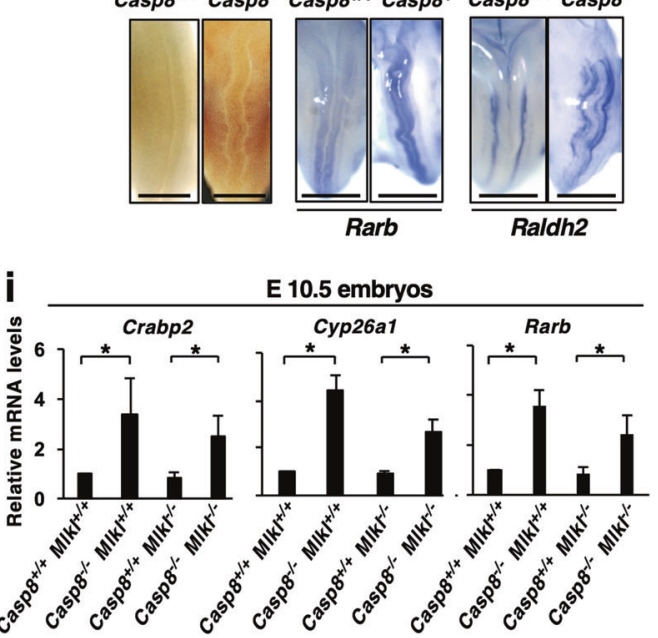

Fig. 8 RA signaling was enhanced in $C a s p 8^{-/-}$mouse embryos. a Immortalized MEFs derived from Wt $\left(\operatorname{Casp} 8^{+/+}\right)$and $\operatorname{Casp8^{-/-}}$ embryos were subjected to western blot analysis for Caspase- 8 and RIPK3. b qRT-PCR analysis of RA-induced genes, Crabp2, Cyp26a1, and Rarb, was carried out in $\operatorname{Casp} 8^{+/+}$and $\operatorname{Casp} 8^{-1-}$ MEFs after treatment with or without $1 \mu \mathrm{M}$ RA for $24 \mathrm{~h}$. c Dual-luciferase reporter analysis of RARE was carried out using RA-treated $\operatorname{Casp} 8^{+/+}$and Casp $8^{-1-}$ MEFs. d qRT-PCR analysis of RA-inducible genes, Crabp2, Cyp26a1, and Rarb, was performed in E10.5 Wt $\left(\right.$ Casp $\left.^{+/+}\right)$and Casp $8^{-1-}$ littermates $(n=10)$. RNA was extracted from whole embryos. e Expressions of RA-inducible genes, Crabp2, Cyp26a1, and
Rarb were analyzed in E10.5 or E11.5 Wt $\left(\operatorname{Casp}^{+/+}\right)$and $C a s p 8^{-/-}$ littermates by whole-mount in situ hybridization analysis. Scale bars, $2 \mathrm{~mm}$. f, g Whole-mount in situ hybridization analysis of Rarb and Raldh2 was carried out using E11.5 Casp $^{-/-}$embryos $(n=5)$. Scale bars, $2 \mathrm{~mm}$. Views of heart and AGM (f), and neural tube (g) were shown. Scale bars, $1 \mathrm{~mm}$. h Whole-mount in situ hybridization analysis of Rarb was carried out using representative E11.5 embryos with the indicated genotypes $(n=5)$. Scale bars, $2 \mathrm{~mm}$. i qRT-PCR analysis of RA-inducible genes, Crabp2, Cyp26al, and Rarb, was carried out as described in d. $* * p<0.01$ and $* p<0.05$

Fig. S14a-d). MEFs derived from the $M l k l^{-/-}$embryos were resistant to TNF $\alpha$-induced necroptosis but not to $\mathrm{TNF} \alpha$-induced apoptosis (Supplementary Fig. S14e). In addition, $M l k l \mathrm{KO}$ rescued the embryonic lethality caused by loss of Casp 8 gene (Supplementary Fig. S14f). Then, we analyzed the effect of loss of Mlkl expression on the expression of RA-specific target genes in $\operatorname{Casp} 8^{-1-}$ mice. Whole-mount in situ hybridization and qRT-PCR analyses revealed that the enhanced expression of Crabp2, Cyp26al, and Rarb was observed in Casp $8^{-1-} M l k l^{-1-}$ embryos (Fig. 8h, i). Taken together, the enhancement of necroptosis, but not enhancement of RA signaling, by loss of Casp 8 expression is essential for embryonic lethality of $\operatorname{Casp} 8^{-/-}$mice, while the augmentation of RA signaling may be involved in the enhancement of necroptosis thorough improvement of RA-induced expression of Mlkl, Ripkl, and Ripk3. 


\section{Discussion}

RA-induced necroptosis was observed in EBs derived from Casp8 KD ES and P19 cells, but not in either Casp8 KD ES and P19 cells without EB formation. RA-induced necroptosis seems to be induced in only EB or its related early embryo. In addition, the enhanced expressions of Ripk1, Ripk3, and Mlkl were observed not only in RAtreated EBs derived from Casp 8 KD ES cells but also in Casp8-deficient E10.5 embryos. The expression level of $\mathrm{TNF} \alpha$ also increased in EBs derived from Casp 8 KD ES cells after RA treatment. RA treatment might be able to induce necroptosis in EBs and early embryos through the enhanced expression of these necroptosis-related genes in the absence of the Casp 8 expression. The mechanism that controls the enhanced expression of these genes specifically in EBs or early embryo is a next question to be clarified.

Nuclear translocation of RIPKs was reported in TNFoinduced necroptosis [48, 49]. Our observations indicated that RIPKs translocated into the nucleus and bound to RAR $\alpha$ by inhibition of Caspase- 8 activity. Recently, RAR $\gamma$ was reported to translocate to cytoplasm and to bind to RIPK1 [50]. Taken together, RARs might have a potential to bind to RIPKs, and therefore RAR $\alpha$ and RAR $\gamma$ might be able to bind to RIPK1 and RIPK3 in the nucleus and RIPK1 in the cytoplasm, respectively.

The embryonic lethality of $\operatorname{Casp} 8^{-/-}$embryos is rescued by not only depletion of Ripk3 $[10,16]$ but also knock-in of kinase-negative K51A Ripk3 [51], indicating that kinase activity of RIPK3, which is indispensable for induction of necroptosis, is required for embryonic lethality of $\operatorname{Casp} 8^{-/-}$ embryos. Recently, $\Delta$ RHIM domain mutant in Ripk3 gene was reported to rescue the embryonic lethality at E 11.5 of Fadd $^{-I-}$ mice [52]. In addition, $\operatorname{Casp}^{-/-} \mathrm{Mlkl}^{-/-}$mice were reported to be viable and to mature into fertile adults [17]. In contrast, RHIM domain of RIPK3, but not kinase activity of RIPK3, are required for the enhancement of RA signaling in Casp 8 KD ES cells. All the data indicate that the embryonic lethality of $\operatorname{Casp8^{-/-}}$ mice is due to excess necroptosis $[10,16,17]$, but not due to the enhancement of RA-induced differentiation. On the other hand, elimination of TNFR1 from $\mathrm{Casp}^{-/-}$embryos was reported to delay embryonic lethality from E11.5 until E16.5 [53], indicating the essential role of TNF $\alpha$-induced necroptosis in the embryonic lethality of E11.5 $\mathrm{Casp}^{-/-}$mice. TNF $\alpha$ was shown to induce necroptosis in RA-treated but not RA-untreated EBs derived from Casp 8 KD ES cells, and the expression level of TNF $\alpha$ was shown to increase after RA treatment in Casp 8 KD ES cells-derived EBs. Taken together, we suppose that Ripkl, Ripk3, Mlkl, and TNF $\alpha$ expressions are enhanced by RA in Casp $8^{-/-}$embryos, and their increased expressions might be partly involved in the embryonic lethality of $\operatorname{Casp}^{-/-}$mice around E10.5 through enhancing the sensitivity to TNF $\alpha$ induced necroptosis (Supplementary Fig. S15).

Acknowledgements We thank J. A. Hejna for advice and critical reading of the manuscript, and all members of the Yonehara laboratory for helpful discussions. We are grateful to M. Matsumiya, Y. Harima, T. Ohtsuka and R. Kageyama for in situ hybridization analyses. This work was supported in part by the Grant-in-Aid for Scientific Research on Innovative Areas (Homeostatic regulation by various types of cell death) from the Ministry of Education, Culture, Sports, Science and Technology (MEXT) of Japan (15H01376 to SY).

\section{Compliance with ethical standards}

Conflict of interest The authors declare that they have no conflict of interest.

Publisher's note Springer Nature remains neutral with regard to jurisdictional claims in published maps and institutional affiliations.

Open Access This article is licensed under a Creative Commons Attribution 4.0 International License, which permits use, sharing, adaptation, distribution and reproduction in any medium or format, as long as you give appropriate credit to the original author(s) and the source, provide a link to the Creative Commons license, and indicate if changes were made. The images or other third party material in this article are included in the article's Creative Commons license, unless indicated otherwise in a credit line to the material. If material is not included in the article's Creative Commons license and your intended use is not permitted by statutory regulation or exceeds the permitted use, you will need to obtain permission directly from the copyright holder. To view a copy of this license, visit http://creativecommons. org/licenses/by/4.0/.

\section{References}

1. Alnemri E. Mammalian cell death proteases: a family of highly conserved aspartate specific cysteine proteases. J Cell Biochem. 1997;64:33-42.

2. Chinnaiyan AM, O'Rourke K, Lane BR, Dixit VM. Interaction of CED-4 with CED-3 and CED-9: a molecular framework for cell death. Science. 1997;275:1122-6.

3. Green D. Apoptotic pathways: ten minutes to dead. Cell. 2005;121:671-4.

4. Salvesen GS, Dixit VM. Caspases: intracellular signaling by proteolysis. Cell. 1997;91:443-6.

5. Yonehara S, Ishii A, Yonehara M. A cell-killing monoclonal antibody (anti-Fas) to a cell surface antigen co-downregulated with the receptor of tumor necrosis factor. J Exp Med. 1989;169:1747-56.

6. Itoh N, Yonehara S, Ishii A, Yonehara M, Mizushima S, Sameshima M, et al. The polypeptide encoded by the cDNA for human cell surface antigen Fas can mediate apoptosis. Cell. 1991;66:233-43.

7. Muzio M, Chinnaiyan AM, Kischkel FC, O'Rourke K, Shevchenko A, Ni J, et al. FLICE, a novel FADD-homologous ICE/ CED-3-like protease, is recruited to the CD95 (Fas/APO-1) deathinducing signaling complex. Cell. 1996;85:817-27.

8. Thornberry NA, Lazebnik Y. Caspases: enemies within. Science. 1998;281:1312-6.

9. Varfolomeev EE, Schuchmann M, Luria V, Chiannilkulchai N, Beckmann JS, Mett IL, et al. Targeted disruption of the mouse Caspase 8 gene ablates cell death induction by the TNF receptors, 
Fas/Apo1, and DR3 and is lethal prenatally. Immunity. 1998;9:267-76.

10. Oberst A, Dillon C, Weinlich R, McCormick LL, Fitzgerald P, Pop C, et al. Catalytic activity of the Caspase-8-FLIP(L) complex inhibits RIPK3-dependent necrosis. Nature. 2011;471:363-7.

11. Hitomi J, Christofferson DE, Ng A, Yao J, Degterev A, Xavier RJ, et al. Identification of a molecular signaling network that regulates a cellular necrotic cell death pathway. Cell. 2008;135:1311-23.

12. He S, Wang L, Miao L, Wang T, Du F, Zhao L, et al. Receptor interacting protein kinase-3 determines cellular necrotic response to TNF-alpha. Cell. 2009;137:1100-11.

13. Zhang DW, Shao J, Lin J, Zhang N, Lu BJ, Lin SC, et al. RIP3, an energy metabolism regulator that switches TNF-induced cell death from apoptosis to necrosis. Science. 2009;325:332-6.

14. Wang H, Sun L, Su L, Rizo J, Liu L, Wang LF, et al. Mixed lineage kinase domain-like protein MLKL causes necrotic membrane disruption upon phosphorylation by RIP3. Mol Cell. 2014;54:133-46.

15. Sakamaki K, Inoue T, Asano M, Sudo K, Kazama H, Sakagami J, et al. Ex vivo whole-embryo culture of Caspase-8-deficient embryos normalize their aberrant phenotypes in the developing neural tube and heart. Cell Death Differ. 2002;9:1196-206.

16. Kaiser WJ, Upton JW, Long AB, Livingston-Rosanoff D, DaleyBauer LP, Hakem R, et al. RIP3 mediates the embryonic lethality of Caspase-8-deficient mice. Nature. 2011;471:368-72.

17. Alvarez-Diaz S, Dillon CP, Lalaoui N, Tanzer MC, Rodriguez DA, Lin A, et al. The seudokinase MLKL and the kinase RIPK3 have distinct roles in autoimmune disease caused by loss of deathreceptor-induced apoptosis. Immunity. 2016;45:513-26.

18. Mark M, Ghyselinck NB, Chambon P. Function of retinoid nuclear receptors: lessons from genetic and pharmacological dissections of the retinoic acid signaling pathway during mouse embryogenesis. Annu Rev Pharm Toxicol. 2005;46:451-80.

19. Duester G. Retinoic acid synthesis and signaling during early organogenesis. Cell. 2008;134:921-31.

20. Rhinn M, Dolle P. Retinoic acid signaling during development. Development. 2012;139:843-58.

21. Dolle P, Ruberte E, Kastner P, Petkovich M, Stoner CM, Gudas LJ, et al. Differential expression of genes encoding alpha, beta and gamma retinoic acid receptors and CRABP in the developing limbs of the mouse. Nature. 1989;342:702-5.

22. Mangelsdorf DJ, Ong ES, Dyck JA, Evans RM. Nuclear receptor that identifies a novel retinoic acid response pathway. Nature. 1990;345:224-9.

23. Mangelsdorf DJ, Umesono K, Kliewer SA, Borgmeyer U, Ong ES, Evans RM. A direct repeat in the cellular retinol-binding protein type II gene confers differential regulation by RXR and RAR. Cell. 1991;66:555-61.

24. Durand B, Saunders M, Leroy P, Leid M, Chambon P. All-trans and 9-cis retinoic acid induction of CRABPII transcription is mediated by RAR-RXR heterodimers bound to DR1 and DR2 repeated motifs. Cell. 1992;71:73-85.

25. Wang ZY, Chen Z. Acute promyelocytic leukemia: from highly fatal to highly curable. Blood. 2008;111:2505-15.

26. Ablain J, Rice K, Soilihi H, de Reynies A, Minucci S, de The H. Activation of a promyelocytic leukemia-tumor protein 53 axis underlies acute promyelocytic leukemia cure. Nat Med. 2014;20:167-74.

27. Minamida Y, Someda M, Yonehara S. FLASH/casp8ap2 is indispensable for early embryogenesis but dispensable for proliferation and differentiation of ES cells. PLoS ONE. 2014;9:e108032.

28. Harima Y, Takashima Y, Ueda Y, Ohtsuka T, Kageyama R. Accelerating the tempo of the segmentation clock by reducing the number of introns in the Hes7 gene. Cell Rep. 2013;3:1-7.

29. Matsumiya M, Tomita T, Yoshioka-Kobayashi K, Isomura A, Kageyama R. ES cell-derived presomitic mesoderm-like tissues for analysis of synchronized oscillations in the segmentation clock. Development. 2018;145:dev.156836.

30. Lee TI, Johnstone SE, Young RA. Chromatin immunoprecipitation and microarray-based analysis of protein location. Nat Protoc. 2006;1:729-48.

31. Cong L, Ran FA, Cox D, Lin SL, Barretto R, Habib N, et al. Multiplex genome engineering using CRISPR/Cas systems. Science. 2013;339:819-23.

32. Kobayashi Y, Yonehara S. Novel cell death by downregulation of eEF1A1 expression in tetraploids. Cell Death Differ. 2009;16:139-50.

33. Watanabe K, Kamiya D, Nishiyama A, Katayama T, Nozaki S, Kawasaki H, et al. Directed differentiation of telencephalic precursors from embryonic stem cells. Nat Neurosci. 2005;8:288-96.

34. Rossant J, Zirngibl R, Cado D, Shago M, Giguere V. Expression of a retinoic acid response element-hsplacZ transgene defines specific domains of transcriptional activity during mouse embryogenesis. Genes Dev. 1991;5:1333-44.

35. Astrom A, Pettersson U, Chambon P, Voorhees JJ. Retinoic acid induction of human cellular retinoic acid-binding protein-II gene transcription is mediated by retinoic acid receptor-retinoid $\mathrm{X}$ receptor heterodimers bound to one far upstream retinoic acidresponsive element with 5-base pair spacing. J Biol Chem. 1994;269:22334-9.

36. Ogura T, Evans RM. A retinoic acid-triggered cascade of HOXB1 gene activation. Proc Natl Acad Sci USA. 1995;92:387-91.

37. Loudig O, Babichuk C, White J, Abu-Abed S, Mueller C, Petkovich M. Cytochrome P450RAI(CYP26) promoter: a distinct composite retinoic acid response element underlies the complex regulation of retinoic acid metabolism. Mol Endocrino. 2000;14:1483-97.

38. Horton C, Maden M. Endogenous distribution of retinoids during normal development and teratogenesis in the mouse embryo. Dev Dyn. 1995;202:312-23.

39. Zelent A, Krust A, Petkovich M, Kastner P, Chambon P. Cloning of murine alpha and beta retinoic acid receptors and a novel receptor gamma predominantly expressed in skin. Nature. 1989;339:714-7.

40. Mattei MG, Riviere M, Krust A, Ingvarsson S, Vennstrom B, Islam MQ, et al. Chromosomal assignment of retinoic acid receptor (RAR) genes in the human, mouse, and rat genomes. Genomics. 1991;10:1061-9.

41. Kikuchi M, Kuroki S, Kayama M, Sakaguchi S, Lee KK, Yonehara S. Protease activity of procaspase- 8 is essential for cell survival by inhibiting both apoptotic and nonapoptotic cell death dependent on receptor-interacting protein kinase 1 (RIP1) and RIP3. J Bio Chem. 2012;287:41165-73.

42. Degterev A, Huang Z, Boyce M, Li Y, Jagtap P, Mizushima N, et al. Chemical inhibitor of nonapoptotic cell death with therapeutic potential for ischemic brain injury. Nat Chem Biol. 2005;1:112-9.

43. Yang Y, Ma J, Chen Y, Wu M. Nucleocytoplasmic shuttling of receptor-interacting protein 3 (RIP3): identification of novel nuclear export and import signals in RIP3. J Biol Chem. 2004;279:38820-9.

44. Um S, Harbers M, Benecke A, Pierrat B, Losson R, Chambon P. Retinoic acid receptors interact physically and functionally with the T:G mismatch-specific thymine-DNA glycosylase. J Biol Chem. 1998;273:20728-36.

45. Lee S, Lee B, Lee JW, Lee SK. Retinoid signaling and neurogenin2 function are coupled for the specification of spinal motor neurons through a chromatin modifier CBP. Neuron. 2009;62:641-54.

46. Cortellino S, Xu J, Sannai M, Moore R, Caretti E, Cigliano A, et al. Thymine DNA glycosylase is essential for active DNA demethylation by linked deamination-base excision repair. Cell. 2011;146:67-79. 
47. le Maire A, Teyssier C, Erb C, Grimaldi M, Alvarez S, de Lera $\mathrm{AR}$, et al. A unique secondary-structure switch controls constitutive gene repression by retinoic acid receptor. Nat Struct Mol Biol. 2010;17:801-7.

48. Yoon S, Bogdanov K, Kovalenko A, Wallach D. Necroptosis is preceded by nuclear translocation of the signaling proteins that induce it. Cell Death Differ. 2016;23:253-60.

49. Weber K, Roelandt R, Bruggeman I, Estornes Y, Vandenabeele P. Nuclear RIPK3 and MLKL contribute to cytosolic necrosome formation and necroptosis. Commun Biol. 2018;1:6.

50. Xu Q, Jitkaew S, Choksi S, Kadigamuwa C, Qu J, Choe M, et al. The cytoplasmic nuclear receptor RARgamma controls RIP1 initiated cell death when cIAP activity is inhibited. Nat commun. 2017;8:425.

51. Mandal P, Berger SB, Pillay S, Moriwaki K, Huang C, Guo H, et al. RIP3 induces apoptosis independent of pronecrotic kinase activity. Mol Cell. 2014;56:481-95.

52. Moriwaki K, Balaji S, Bertin J, Gough PJJ, Chan FK. Distinct kinase-independent role of RIPK3 in CD11 $\mathrm{c}^{+}$mononuclear phagocytes in cytokine-induced tissue repair. Cell Rep. 2017;18:2441-51.

53. Dillon CP, Weinlich R, Rodriguez DA, Cripps JG, Quarato G, Gurung P, et al. RIPK1 blocks early postnatal lethality mediated by Caspase-8 and RIPK3. Cell. 2014;157:1189-202. 